\title{
The Paradox of a Radiculous Maxillary Second Premolar: A Case Report
}

\author{
${ }^{1}$ Beble Gorakh D, ${ }^{2}$ Margasahayam Sumanthini V, ${ }^{3}$ Shenoy Vanitha U, ${ }^{4}$ Patil Anuradha B
}

\begin{abstract}
The major causes for persistent intracanal infection are unfilled canals and incomplete obturation resulting in endodontic failure. A thorough knowledge of the root canal anatomy and accurate interpretation of preoperative radiographs are essential aspects of endodontic therapy. Quite often the third root or canal is missed as it is not visible under normal vision. Three rooted maxillary premolars have similar root canal morphology as that of maxillary molars and are described as 'Radiculous'. According to Vertucci, the incidence of three canals in maxillary second premolar is 0.3 to $2 \%$. This case report describes the clinical diagnosis and endodontic retreatment of radiculous maxillary second premolar, drawing particular attention to access refinements aided by ultrasonics and dental operating microscope.
\end{abstract}

Key-words: Magnification, Radiculous, Retreatment, Ultrasonics

How to cite this article: Gorakh BD, Sumanthini MV, Shenoy VU, Anuradha PB. The Paradox of a Radiculous Maxillary Second Premolar: A Case Report. J Contemp Dent 2018;8(2):106-111.

\section{Source of support: Nil}

Conflict of interest: None

\section{INTRODUCTION}

A thorough understanding of the variations in root canal morphology and correct evaluation of preoperative radiographs are essential aspects of endodontic therapy. One of the primary factors for endodontic treatment failure is undetected extra canals. ${ }^{1}$ The variations in the root canal morphology pose difficulties to the clinician during all the operative stages, including access cavity design preparation, chemomechanical debridement followed by obturation of the root canal system.

Anatomical variations in the root canal morphology of maxillary premolars have been reported in a number

\footnotetext{
${ }^{1}$ Postgraduate Student, ${ }^{2}$ Professor, ${ }^{3}$ Professor and HOD, ${ }^{4}$ Reader

${ }^{1-4}$ Department of Conservative Dentistry and Endodontics, Mahatama Gandhi Mission's Dental College and Hospital, Kamothe, Navi Mumbai, Maharashtra, India
}

Corresponding Author: Beble Gorakh D, Department of Conservative Dentistry and Endodontics, Mahatama Gandhi Mission's Dental College and Hospital, Kamothe, Navi Mumbai, Maharashtra, India, Phone: +91 8108208217, Email: gorubeble@gmail.com of in vitro studies. ${ }^{1-3}$ Vertucci reported an incidence of 0.3 to $2 \%$ occurrence of three root canals in maxillary second premolar. ${ }^{4}$ Bellizzi in 1985 in his in vivo radiographic study found that out of 630 maxillary second premolars, one canal was seen in $40.3 \%$ (254), two canals were seen in $58.6 \%$ (369) and three canals were seen in $1.1 \% .{ }^{5}$ According to a study done by Raj and Sumitha in 2010, out of 200 maxillary second premolars of Indian population examined by clearing technique; Vertucci's Type II configuration was the most prevalent $(33.6 \%)$. This was followed by Type II (31.1\%), Type I (29.2\%), Type V (2.1\%), Type III (1.3\%), Type VI (1.2\%) and Type VII $(1 \%)^{6}$ (Fig. 1). ${ }^{4}$ Three-rooted maxillary premolars have root canal morphology similar to maxillary molars, and were termed as "mini molars" or "radiculous" by Maibum ${ }^{7}$ and Goon $^{8}$ respectively.

Magnifying visual aid such as the dental operating microscope (DOM), has shown promise in detecting and treatment of canal variations without incurring much damage to tooth structure. ${ }^{9}$ This case report describes the management of a radiculous second premolar under DOM.

\section{CASE REPORT}

A 24-year-old male patient reported to the Department of Conservative Dentistry and Endodontics with the chief complaint of pain and food lodgement in the upper left back tooth region since two weeks. Patient experienced mild, intermittent, non radiating pain on mastication in the maxillary left posterior teeth region that relieved without any medications. Patient had undergone end-

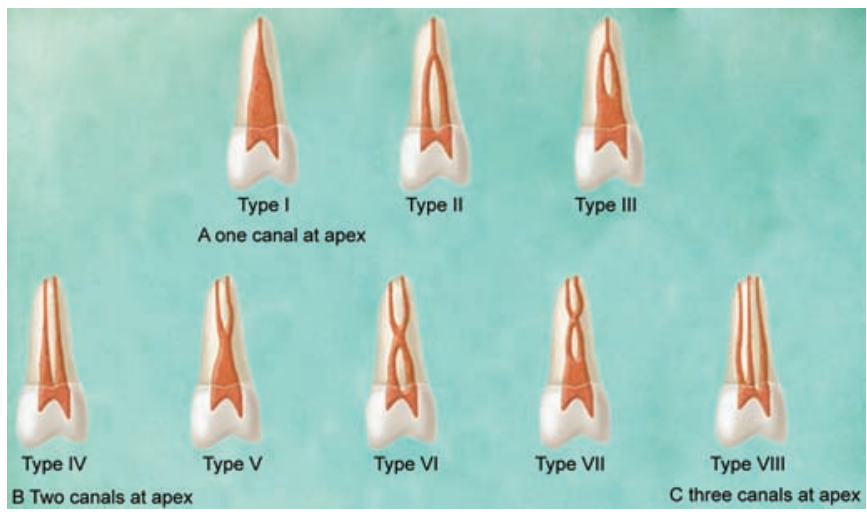

Fig. 1: Diagrammatic representation of Vertucci's canal configurations. ${ }^{4}$ 
odontic therapy with maxillary left second premolar 2 years ago. Clinical examination revealed no extra or intraoral soft tissue abnormalities; the probing depth was within normal limits, and the affected tooth was tender to vertical percussion. The tooth showed proximal caries mesially. There was no coronal restoration present. Preoperative radiographs revealed unsatisfactory obturation and presence of an extra root outline distally suggestive of an extra root widening of the periodontal ligament was evident with the palatal root (Fig. 2). A diagnosis of previously treated tooth with symptomatic apical periodontitis was made. Medical history was non contributory. Thus, the treatment plan decided was non surgical endodontic retreatment. Patient consent was obtained and treatment was initiated.

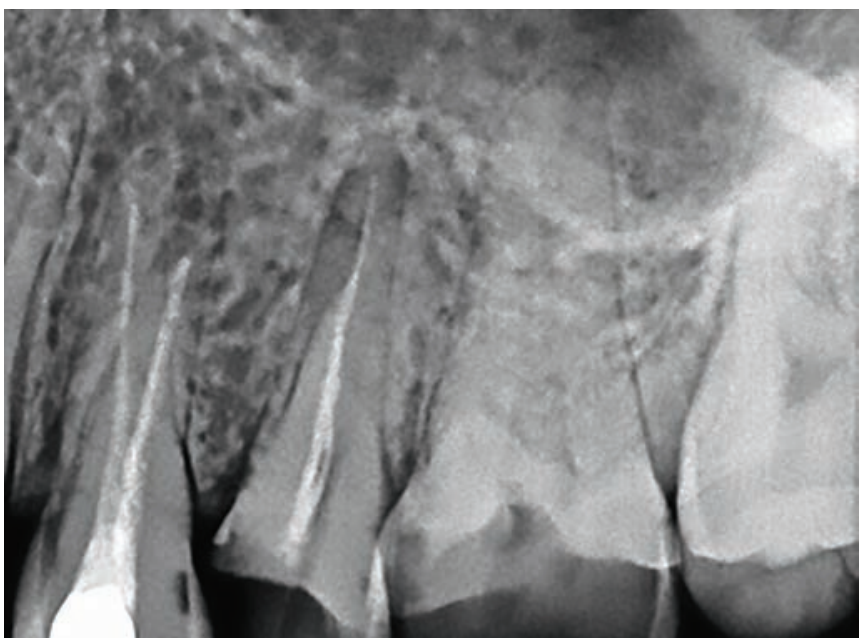

Fig. 2: Preoperative intraoral periapical radiograph of 25 showing unsatisfactory obturation and widening of PDL space

The retreatment procedure was initiated under rubber dam isolation in the left maxillary second premolar. The access cavity was re-entered using a number 2 round carbide bur. Gutta percha was detected in the palatal canal only. Coronal flaring was done using gates glidden drill number \#1 and \#2 (Mani Inc, Japan). Previous root canal filling (RCF) material was removed completely using Hedstrom file (\#15-40, Mani Inc, Japan) along with xylene (Fischer scientific, Thermo Electron LLS India Pvt Ltd) in a crown-down technique. The removal of RCF material was verified radiographically (Fig. 3).

On clinical examination of access cavity, it was seen that the buccal orifice was eccentric in location. Access cavity was visualized under DOM (OPMI Pico,Carl Zeiss Pvt Ltd, Germany) at 1.6 X magnification and access refinement was made distally using ET18D Ultrasonic tip (US tip), (EndoSuccess Retreatment Kit; Acteon, Merignac, France) at power setting of 3 (Fig. 4). The access cavity was triangular in outline (Fig. 5). The buccal canal was seen bifurcating $5 \mathrm{~mm}$ below the level of pulpal floor into mesiobuccal and distobuccal canal (Fig. 6). The canals

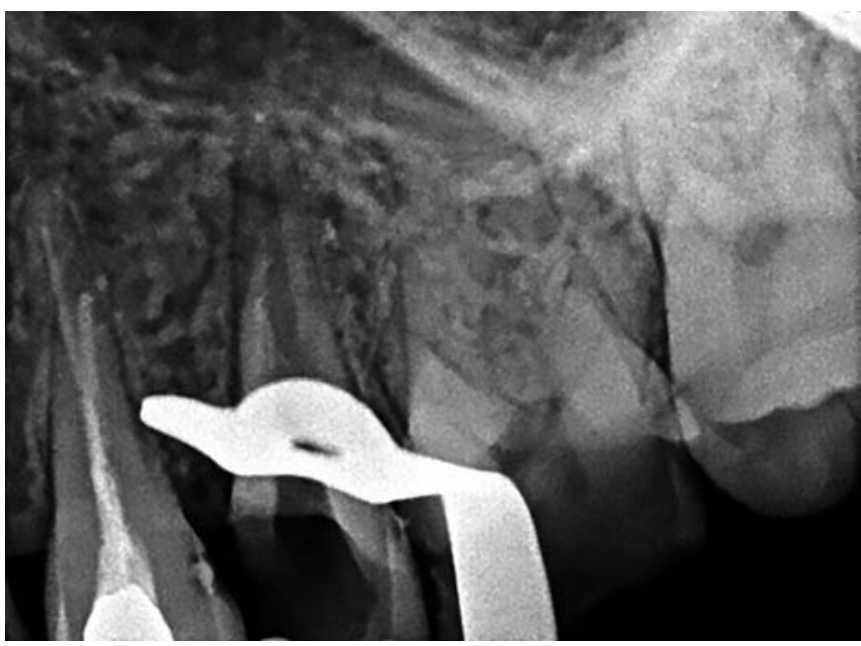

Fig. 3: Radiograph of 25 showing complete removal of previous root canal filling material

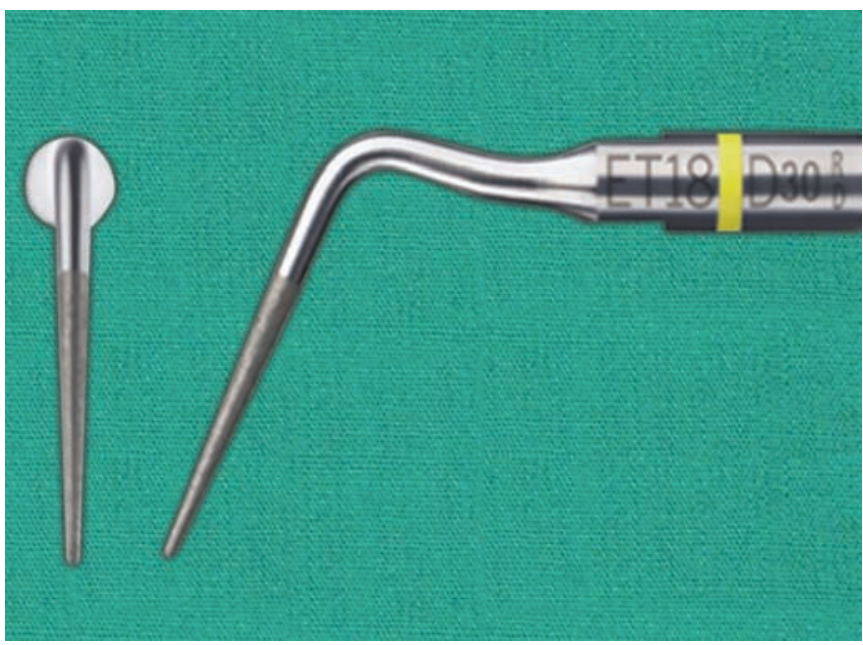

Fig. 4: ET18D US tip

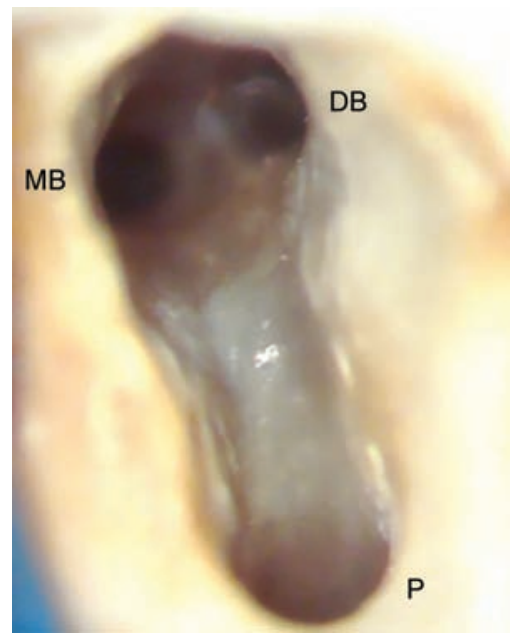

Fig. 5: T" shape access cavity preparation of 25 visualized under dental operating microscope (DOM) at 1.6X magnification showing three canal orifices-mesiobuccal (MB), distobuccal (DB) and palatal $(\mathrm{P})$

were scouted with \#10 k file (Mani Inc, Japan). Tentative working length was determined using electronic apex locator [Raypex5, Verein Deutscher Werkzeugmaschinenfabriken (VDW), Munich, Germany] and verified radio- 


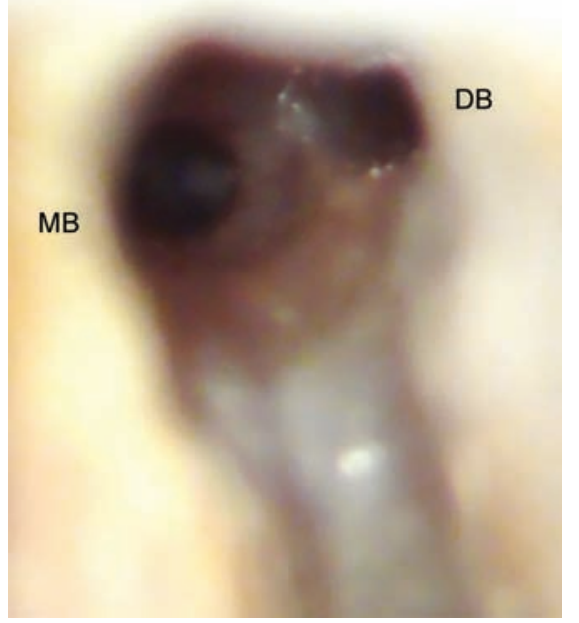

Fig. 6: DOM image of 25 showing the deep bifurcation of the main buccal canal into mesiobuccal (MB) and distobuccal (DB) canals viewed at $1.6 \mathrm{X}$ magnification

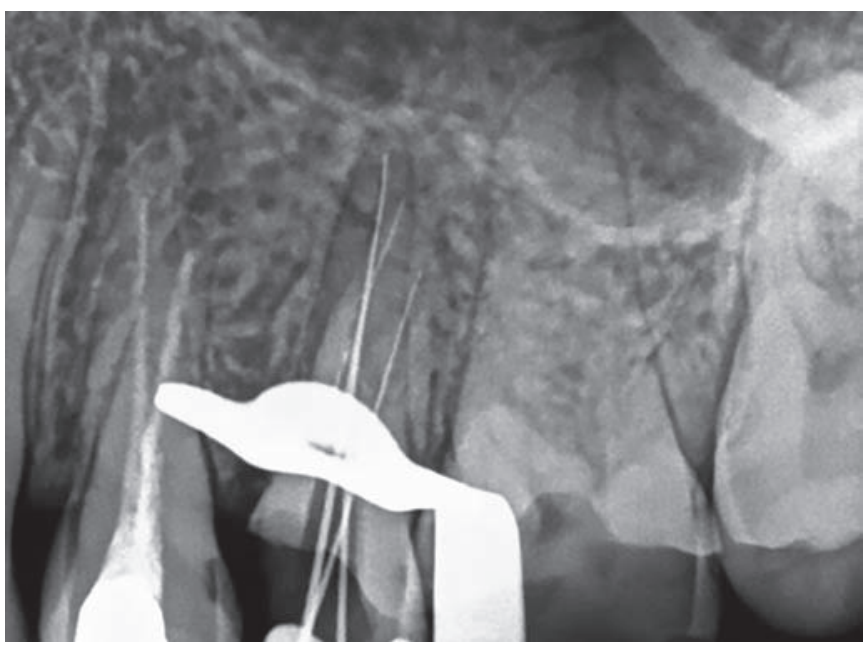

Fig. 7: Working length radiograph of 25

graphically (Fig. 7). Cleaning and shaping was completed using profile rotary files (Dentsply, Maillefer, Ballaigues, Switzerland) to an apical size preparation of 25/0.06 with both buccal canals and 30/0.06 with palatal canal. The canals were intermittently irrigated with $2.5 \%$ sodium hypochlorite (NaOCl); (Trifarma Pvt Ltd, Bhiwandi, Thane). A total volume of $25 \mathrm{~mL}$ of $2.5 \% \mathrm{NaOCl}$ was used for irrigation during cleaning and shaping procedure. An intracanal medicament of sterile calcium hydroxide $(\mathrm{CH})$ powder (Prodent, Ratnagiri) mixed to a thick consistency with 2\% Chlorhexidine (CHX); (SafePlus, Neelkanth Pvt Ltd, Jodhpur) was placed into the canals for one week. Cotton pellet was placed in the pulp chamber and the access cavity was temporized with zinc oxide eugenol cement (Deepak Enterprise, Mulund, Mumbai ).

In the following appointment, intracanal medicament was removed using $\mathrm{H}$ files and copious saline irrigation. Final irrigation was done using passive ultrasonic activation (PUA) of $2.5 \% \mathrm{NaOCl}$ using a \#20 Irrisafe US tip (Irrisafe tips, Acteon, Merignac, France) at a power setting of 3 for 20 sec cycle using an intermittent flush technique wherein the irrigant was replenished after every cycle. Three cycles were carried out to complete a total activation period of one minute. Similarly, PUA was done using 17\% ethylenediaminetetraacetic acid (EDTA; Dent Wash, Prime Dental Products, Thane) liquid followed by final irrigation with $2 \% \mathrm{CHX}$ for two minutes. Copious saline irrigation was done before each irrigant change. Master cone fit using 6\% gutta-percha cones (Dentsply, Maillefer, Ballaigues, Switzerland) was checked clinically and radiographically (Fig. 8). The canals were dried with absorbent paper points (Sure-endo, Sure Dent Corporation, Gyeonggi-do, Korea) and obturated with $\mathrm{AH}$ Plus root canal sealer (Dentsply, Maillefer, Ballaigues, Switzerland) and gutta percha using lateral compaction technique followed by warm vertical compaction. Obturation radiograph showed satisfactory filling of all three canals along with a lateral canal of palatal root and sealer extrusion was noted with the distobuccal canal (Fig. 9). Intermediate restorative material (IRM, Dentsply India Pvt. Ltd, Delhi, India) was placed as a temporary restora-

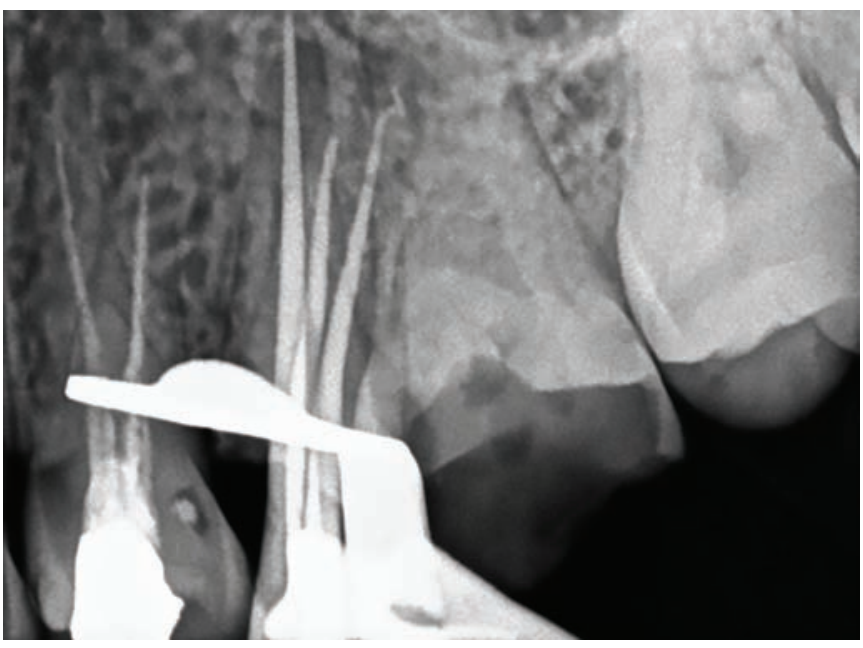

Fig. 8: Master cone selection radiographof 25

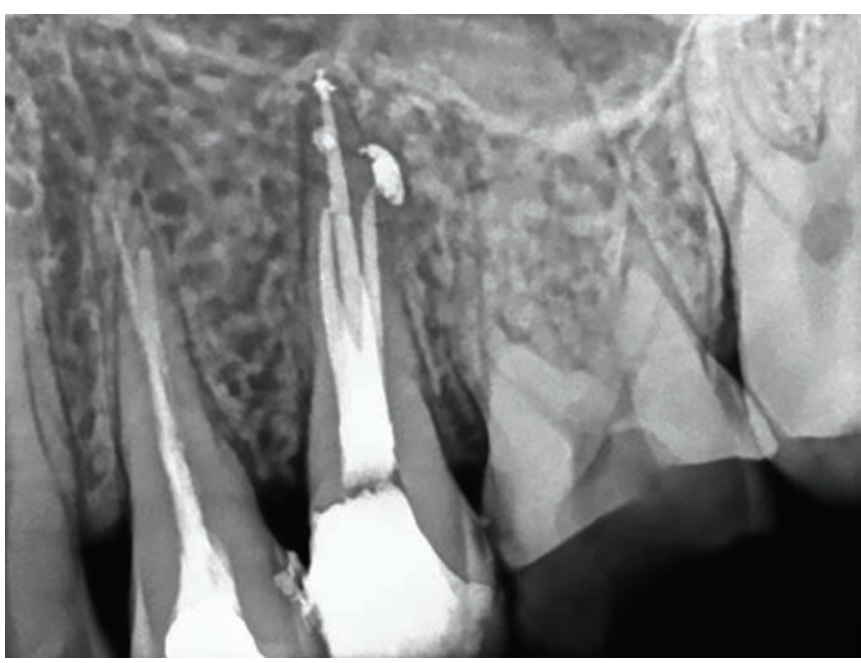

Fig. 9: Obturation radiograph of 25 showing adequate filling of all three canals along with filling of lateral canal in palatal root. Sealer extrusion noted with distobuccal canal 
tion. Patient was evaluated for further post endodontic restoration.

\section{DISCUSSION}

Complete chemomechanical debridement and obturation are essential for the success of endodontic treatment. Clinicians must be well aware of the anatomical variations in the root canal morphology. Failure to locate, negotiate and instrument extra canals can lead to persistent infection, instrumentation errors like perforation, ledging and stripping thereby leading to treatment failure. ${ }^{10}$ Identification of extra canals and root is difficult preoperatively. Although a thorough radiographic examination of tooth can help clinician to recognize extra root from external root outline. Radiographically, an abrupt loss of radiolucent pulp canal space is highly suggestive of an extra canal either in the same root or in other independent roots. Also, in a maxillary premolar whenever the mesiodistal width of a root in the middle third area is equal to or greater than the mesiodistal width of the crown, it may be suggestive of a three rooted anatomy. ${ }^{11}$

Bellizzi has classified root morphology of maxillary second premolars into the following three groups namely: (1) three fused roots or fused buccal roots and a partially fused or separated palatal root; (2) buccal roots fused at the middle or apical third, and with a separated or partially fused palatal root; and (3) all three roots separated at the cervical third. ${ }^{5}$ In the present case report, the root canal system could be classified as Type III as per Gulabivala classification wherein first canal orifice divides into two different canals and second canal orifice exists as a single canal; thus two canal orifices exit as three different portals (Fig. 10). ${ }^{12}$ According to the new classification given by Ahmed et al. in 2016, the radiculous premolar can be classified as $25 \mathrm{~B}^{1-2} \mathrm{P}^{1}$ where in $\mathrm{B}^{1-2}$ denotes buccal

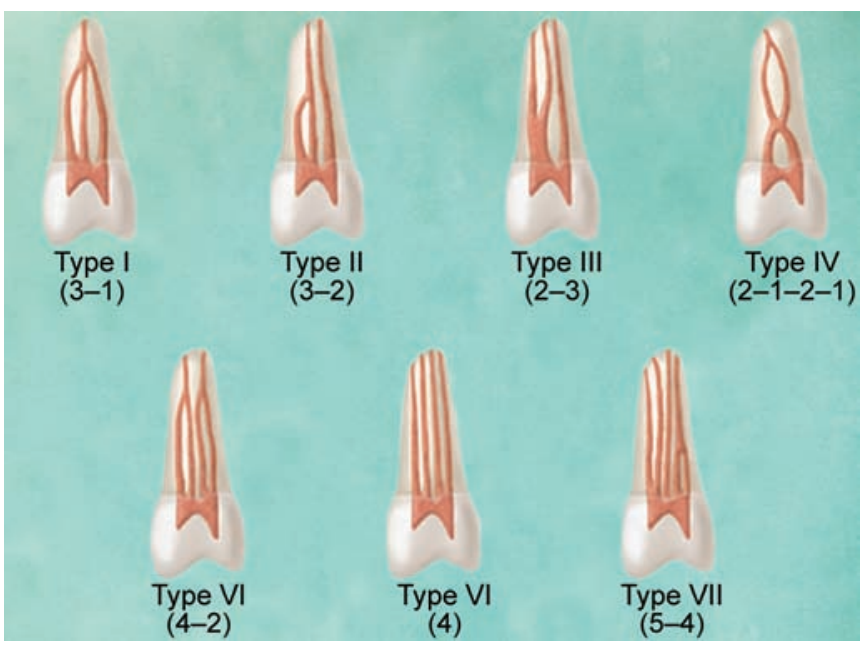

Fig. 10: Diagrammatic representation of Gulabivala and coworkers' supplemental canal configurations. ${ }^{12}$

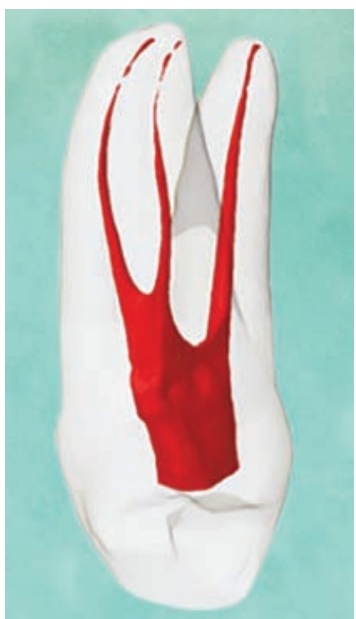

Fig. 11: Diagrammatic representation of maxillary second premolar with three canals classified according to Ahmed et al as $25 \mathrm{~B}^{1-2} \mathrm{P}^{1}$ where in $\mathrm{B}^{1-2}$ denotes buccal root with one orifice dividing into two canals havingtwo separate portal of exits and $\mathrm{P}^{1}$ denotes single palatal canal having one portal of exit ${ }^{13}$

root with one orifice dividing into two canals having two separate portal of exits and $\mathrm{P}^{1}$ denotes single palatal canal having one portal of exit (Fig. 11). ${ }^{13}$

In the present case due to the canal variation noted clinically, dental operating microscope was used. DOM offers homogeneous illumination and a clear visualization of the site. Enhanced illumination and magnification enables the clinician to visualize the operating site and locate root canal orifices. ${ }^{14}$ A T-shape modification of access cavity was done as suggested by Sieraski et al. for maxillary premolar. $^{11}$ The access cavity was extended distally using ET 18D US tip under DOM at 1.6 X magnification (total magnification of $13.6 \mathrm{X}$ ) to uncover the distobuccal orifice. Access refinement ET18D US tip helped in selective dentin removal under magnification. It helps clinician to achieve a conservative approach while treating such aberrant root morphologies as US tips have a longer shank and a fine tip. Ultrasonic tip enables better visibility while working when compared to a conventional airotor/micromotor handpiece. Apart from its benefits, fracture of the ultrasonic tips may occur, representing an iatrogenic problem during canal orifice refinement. The power setting of ultrasonic has a significant influence on cutting, as larger fragments of dentin are removed at higher power. ${ }^{15}$ Also care has to be taken to prevent heat generation during activation of ultrasonics tips in order to prevent deleterious effects on periodontium, bone and adjacent soft tissues. This could be achieved using rubber dam isolation, low power setting and intermittent saline irrigation. Brown et al. in 1970 studied the thermal diffusivity (as a function of thickness and time) and thermal conductivity (as a function of time and temperature) of enamel and dentin. The author stated that dentin is a poor heat conductor, suggesting that the thickness of 
dentin will prevent potential heat damage by providing insulation to the periodontal tissues. Varying thickness of dentin within the same tooth or between tooth types may affect the amount of heat transferred to the external root surface which can be detrimental to the periodontium and lead to bone resorption and/or ankylosis. ${ }^{16}$

Various studies have investigated the temperature above which there can be damage to the surrounding bone. ${ }^{17-21}$ In 1988, Sauk et al. found that when periodontal ligament was exposed to a temperature of $43^{\circ} \mathrm{C}$ resulted in protein denaturation, ankylosis and bone resorption over a period of time. ${ }^{17}$ Matthews and Hirsch studied the effect of temperature on human cortical bone and reported inactivation of bone alkaline phosphatase at $56^{\circ}$. Hence they considered this as the critical temperature for bone injury to occur. ${ }^{18}$ Eriksson et al. in his study observed that blood flow stasis occurs in bone two days after an exposure of 1-minute to a temperature of $53^{\circ} \mathrm{C} .{ }^{19}$ Healing after thermal injury to bone appeared to induce connective tissue rather than hard tissue formation. The critical temperature for bone injury could be as low as $47^{\circ} \mathrm{C}$ and does not exceed more than $10^{\circ} \mathrm{C}$ above body temperature. ${ }^{20} \mathrm{~A}$ case of severe periodontal injury caused by ultrasonic instrumentation resulting in soft tissue and bony necrosis in the facial and mesial aspects of maxillary central incisor along with nasal discharge was reported. This occurred probably due to inadvertent thermal injury caused by overheating of tooth while ultrasonic instrumentation. ${ }^{21}$ In another study, extracted teeth were instrumented by conventional mechanical techniques and by ultrasonic driven instruments. The author reported that ultrasonic instruments caused a high temperature on the root surface, suggesting that continuous irrigation should be used during instrumentation. Heat generated within the root canal may heat the dentin and result in injury of the periodontal ligament and alveolar bone if it is sufficiently intense or prolonged. The threshold for heat-induced bone necrosis is $10^{\circ} \mathrm{C}$ above normal body temperature of $37^{\circ} \mathrm{C}$ when sustained for 1 $\mathrm{min}$. Fatty necrosis of bone occurs and new bone will not regenerate under these conditions. ${ }^{20}$ Eriksson and Albertson studied the heating of implant in rabbit bone and found that that $47^{\circ} \mathrm{C}$ for 1 minute was the threshold for bone survival. Fatty necrosis of bone without regeneration occurred at this threshold. Thus a $10^{\circ} \mathrm{C}$ rise in bone temperature is accepted as the value at which irreversible bone damage may occur. ${ }^{19}$ Hence various studies in literature are a convincing reminder of thermal injuries associated with usage of ultrasonic instruments.

In the present case, PUA was done for one minute with intermittent flush technique. A study done by van der Sluis et al observed when the irrigation time was set at 1 minute, and the $\mathrm{NaOCl}$ refreshed after each ultrasonic activation of 20 seconds, the intermittent flush technique was more efficient removing dentin debris from the root canal than the continuous flush of irrigation..$^{22} \mathrm{~A}$ study done by Krell et al. used 5 minute of activation period using \#15 k file which was found to be efficacious. ${ }^{23}$ In the present case, $\mathrm{CHX}$ was used in irrigation and intracanal medicament. CHX is a well established irrigant with antimicrobial action against both Gram positive and Gram negative bacteria and fungi. The antimicrobial substantivity of CHX is reported upto 12 weeks by Khademi et al in $2006 .{ }^{24} \mathrm{CHX}$ mixed with $\mathrm{CH}$ helps eliminating $\mathrm{E}$. faecalis from the dentinal tubules which is one of the most common organism in retreatment cases..$^{25}$ Hence an intracanal medicament of calcium hydroxide mixed with $2 \% \mathrm{CHX}$ was placed inside all canals.

\section{CONCLUSION}

The endodontic treatment in the maxillary second premolar in the present case report failed due to non recognition of the canal variant. Satisfactory endodontic retreatment was possible essentially due to magnification using DOM and US. Moreover these techniques resulted in conservative access preparation thereby retaining the precious pericervical dentin which may contribute to the clinical longevity of the tooth when in function.

\section{REFERENCES}

1. Ferreira CM, de Moraes IG, Bernardineli N. Three-rooted maxillary second premolar. J Endod 2000;26(2):105-106.

2. Low D. Unusual maxillary second premolar morphology: a case report. Quintessence Int 2001;32(8):626-628.

3. Kartal N, Ozcelik B, Climilli H. Root canal morphology of maxillary premolars. J Endod 1998;24(6):417-419.

4. Vertucci FJ, Selling A, Gills R. Root canal morphology of the maxillary second premolar. Oral Surg Oral Med Oral Pathol 1974;38(3):456-464.

5. Bellizzi R, Hartwell G. Radiographic evaluation of root canal anatomy of in vivo endodontically treated maxillary premolars. J Endod 1985;11(1):37-39.

6. Jayasimha RU, Mylswamy S. Root canal morphology of maxillary second premolars in an Indian population. J Conserv Dent. 2010 Jul;13(3):148-151.

7. Maibaum WW. Endodontic treatment of a "radiculous" maxillary premolar: a case report. Gen Dent. 1989;37(4):340-341.

8. Goon WW. The "radiculous" maxillary premolar: recognition, diagnosis, and case report of surgical intervention. Northwest Dent. 1993;72(2):31-33.

9. Arisu HD, Alacam T. Diagnosis and treatment of three-rooted maxillary premolars. Eur J Dent. 2009;3(1):62-66.

10. Ingle JI. Outcome Of Endodontic Treatment And Re-Treatment. Endodontics. 5th ed. Hamilton(Ontario): BC Decker Inc; 2002. p.752.

11. Sieraski SM, Taylor GN, Kohn RA. Identification and endodontic management of three-canalled maxillary premolars. J Endod 1985;15(1):29-32.

12. Gulabivala K, Aung TH, Alavi A, Mg Y-L: Root and canal morphology of Burmese mandibular molars. Int Endod J 2001;34(5):359-370. 
13. Ahmed HMA, Versiani MA, De-Deus G, Dummer PMH. A new system for classifying root and root canal morphology. Int Endod J 2017;50(8):761-770.

14. Coutinho Filho T, La Cerda RS, Gurgel Filho ED, de Deus GA, Magalhães KM. The influence of the surgical operating microscope in locating the mesiolingual canal orifice: a laboratory analysis. Braz Oral Res. 2006;20(1):59-63.

15. Paz E, Satovsky J, Moldauer I. Comparison of the cutting efficiency of two ultrasonic units utilizing two different tips at two different power settings. J Endod 2005;31(11): 824826.

16. Brown WS, Dewey WA, Jacobs HR. Thermal properties of teeth. J Dent Res 1970;49(4):752-755.

17. Sauk JJ, Norris K, Foster R, Moehring J, Somerman MJ. Expression of heat stress proteins by human periodontal ligament cells. J Oral Pathol 1988;17(9):496-499.

18. Matthews LS, Hirsch C. Temperatures measured in human cortical bone when drilling. J Bone Joint Surg Am 1972;54(2):297-308.

19. Eriksson A, Albrektsson T, Grane B, McQueen D. Thermal injury to bone. A vital microscopic description of heat effects. Int J Oral Surg 1982;11(2):115-121.
20. Huttula AS, Tordik PA, Imamura G, Eichmiller FC, McClanahan SB. The effect of ultrasonic post instrumentation on root surface temperature. J Endod 2006;32(11):10851087.

21. Walters JD1, Rawal SY. Severe periodontal damage by an ultrasonic endodontic device: a case report. Dent Traumatol. 2007;23(2):123-127.

22. vanderSluis LW, GambariniG, Wu MK, WesselinkPR. Theinfluence of volume, type of irrigant and flushing method on removing artificially placed dentine debris from the apical root canal during passive ultrasonic irrigation. IntEndod J 2006;39(6):472-476.

23. Krell KV, Johnson RJ, Madison S. Irrigation patterns during ultrasonic canal instrumentation. Part I. K-type files. J Endod 1988;14(2):65-68.

24. Khademi AA, Mohammadi Z, Havaee A. Evaluation of the antibacterial substantivity of several intra-canal agents. Aust Endod J 2006;32(3):112-115.

25. Basrani B, Tjäderhane L, Santos JM, Pascon E, Grad H, Lawrence HP, Friedman S. Efficacy of chlorhexidine and calcium hydroxide containing medicaments against Enterococcus faecalis in vitro. Oral Surg Oral Med Oral Pathol Oral Radiol Endod 2003;96(5):618-624. 